\title{
Alpha-methyltyrosine in the management of phaeochromocytoma
}

\author{
KN GREEN, SK LARSSON, DG BEEVERS, PG BEVAN, B HAYES
}

\author{
From the Departments of Medicine, Surgery, and Anaesthetics, Dudley Road Hospital, Birmingham
}

\begin{abstract}
Patients with phaeochromocytoma are usually treated with a combination of $\alpha$ - and $\beta$-receptor-blocking drugs in preparation for adrenal surgery. ${ }^{1}$ Beta-blockers are, however, contraindicated in patients with obstructive airways disease or heart failure. We report a patient in whom this medication was contraindicated on both grounds; she had cor pulmonale associated with severe chronic obstructive airways disease and bronchiectasis. We used the tyrosine hydrolase inhibitor $\alpha$-methyltyrosine to block catecholamine synthesis and control pulse and blood pressure before surgery.
\end{abstract}

\section{Case report}

A 37-year-old woman was admitted to hospital with severe bronchopneumonia and cor pulmonale. She had had chronic obstructive airways disease with bronchiectasis since early childhood. At the age of 7 she underwent left pneumonectomy for bronchiectasis, but had continued to produce copious purulent sputum ever since. She had been treated with oral corticosteroids and $\beta$-adrenergicstimulator aerosols for 15 years. At the age of 25 she had to have a pregnancy terminated in the second trimester owing to life-threatening respiratory distress. For one year she had noticed hyperhidrosis, palpitations, and agoraphobia, and had consulted a psychiatrist. Blood pressure measurements in the outpatient clinic had shown mild hypertension, but this had been attributed to the corticosteroid treatment.

When admitted she was very ill with severe respiratory distress and was producing $300 \mathrm{ml}$ sputum daily; she had ankle oedema, hepatomegaly, and a raised jugular venous pressure. She was treated with antibiotics, diuretics, postural drainage, and an increased dosage of corticosteroids. Her respiratory function at the time was grossly impaired: the one-second forced expiratory volume $\left(\mathrm{FEV}_{1}\right)$ was $485 \mathrm{ml}$ (17\% of normal), rising to $646 \mathrm{ml}$ after inhaled salbutamol, and the peak expiratory flow rate (PEFR) 90 $1 /$ min $\left(21 \%\right.$ of normal); oxygen tension $\left(\mathrm{Po}_{2}\right)$ was $7 \cdot 2 \mathrm{kPa}$ $(54 \mathrm{~mm} \mathrm{Hg})$ and carbon dioxide tension $\left(\mathrm{PCO}_{2}\right) 5.9 \mathrm{kPa}$ (44.3 $\mathrm{mm} \mathrm{Hg}$ ). The electrocardiogram (ECG) showed right axis deviation and right ventricular hypertrophy. The patient recovered from this acute illness, but her symptoms of hyperhidrosis, palpitations, and agoraphobia continued, and her blood pressure was noted to fluctuate spontaneously between values of $150 / 90$ and $210 / 150 \mathrm{~mm} \mathrm{Hg}$ and her pulse between 80 and 115 beats per minute. Urinary metadrenaline was $15.8 \mathrm{nmol} / \mathrm{mmol}$ creatinine (normal $<$ 4.8) and normetadrenaline $34.1 \mathrm{nmol} / \mathrm{mmol}$ creatinine (normal $<10 \cdot 2$ ), and urinary total metanephrines varied

Address for reprint requests: Dr DG Beevers, University Department of Medicine, Dudley Road Hospital, Birmingham B18 7QH. from 9.5 to $14 \mathrm{nmol} /$ day (normal $<5 \cdot 5$ ). Serum dopamine $\beta$-hydroxylase was $169 \mathrm{IU} / 1$ (normal 2-100 IU/l). A rightsided adrenal tumour was detected by abdominal ultrasound and aortography.

Beta-adrenergic-receptor-blocking drugs for control of hypertension were contraindicated because of the airways obstruction and heart failure. Propranolol $20 \mathrm{mg}$ (two doses) and later the cardioselective beta-blocker atenolol $100 \mathrm{mg}$ were tried but both had to be discontinued owing to an increase in her breathlessness. Alpha-methyl-ptyrosine, a competitive inhibitor of the enzyme tyrosine hydroxylase, required for the conversion of tyrosine to dopa (fig 1), was administered in a dose of $500 \mathrm{mg}$ daily in addition to corticosteroids, diuretics for control of heart failure, and antibiotics. The patient was temporarily discharged on this regimen and subsequent outpatient blood pressure readings fell to normal, with a modest reduction of urinary metanephrines (fig 2). No clinical side effects of $\alpha$-methyltyrosine were encountered.

One month later the patient's chest condition had improved $\left(\mathrm{FEV}_{1}=657 \mathrm{ml}\right.$, rising to $822 \mathrm{ml}$ after inhaled salbutamol; $\mathrm{Po}_{2} 9.2 \mathrm{kPa}(69 \mathrm{~mm} \mathrm{Hg}), \mathrm{PCO}_{2} 4.9 \mathrm{kPa}(36.8$ $\mathrm{mm} \mathrm{Hg}$ ). Abdominal exploration was performed and a $112-\mathrm{g}$ right adrenal tumour removed. There was no evidence of bilateral tumours and further investigations excluded the multiple endocrine syndrome. Blood pressure

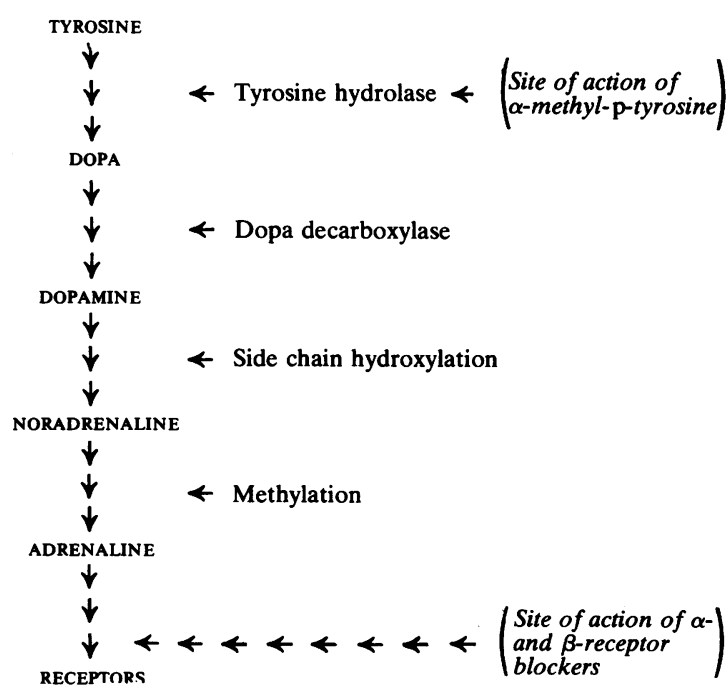

Fig 1 Metabolic pathway of catecholamine synthesis, showing sites of actions of alpha-methyl-p-tyrosine and the adrenergic-receptor blockers. 


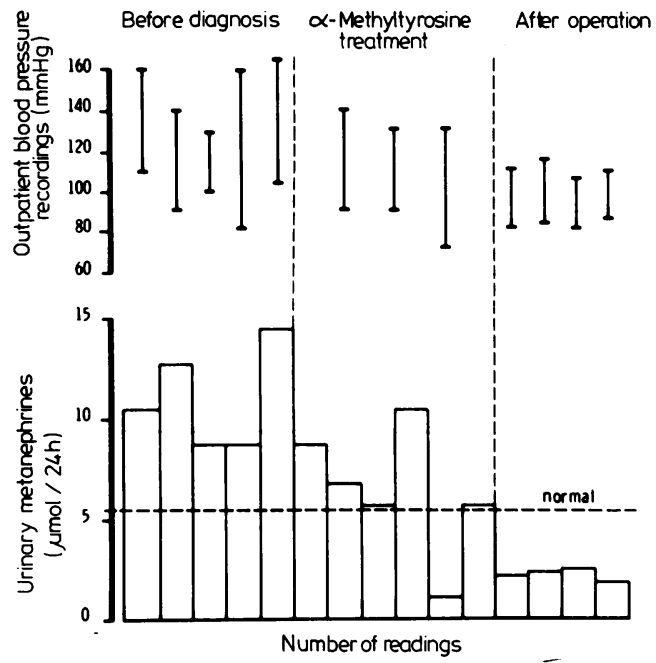

Fig 2 Effect of treatment on blood pressure and urinary metanephrines: outpatient blood pressure readings before treatment, while the patient was receiving $\alpha$-methyltyrosine, and after adrenalectomy, with urinary excretion of total metanephrines.

during the operation was controlled with a nitroprusside infusion and an intravenous bolus of practolol. ${ }^{2}$ Postoperative recovery was uneventful, and there has been no clinical recurrence of signs of heart failure or hypertension, despite discontinuation of diuretics and $\alpha$-methyltyrosine. Hyperhidrosis and agoraphobia have also disappeared. Since removal of the tumour the urinary metanephrine values and blood pressure recordings at outpatient attendances have both returned to normal. The PEFR measured after removal of the tumour was $1401 / \mathrm{min}$; in the years before surgery PEFR had been below $1001 / \mathrm{min}$ on all save one occasion.

\section{Discussion}

Beta-blockers can usually be used in the preoperative management of phaeochromocytoma. These drugs block only the beta-adrenergic receptors and the high levels of adrenaline and noradrenaline that remain may still produce toxic myocarditis. ${ }^{3}$ Possibly the heart failure in our patient was aggravated by a degree of myocarditis, and this may explain the complete absence of signs of failure without diuretic treatment for the 16 months since operation.

Good control of blood pressure may clearly be achieved in patients with phaeochromocytoma treated with $\alpha$-methyltyrosine. ${ }^{45}$ While our patient's blood pressure was reduced to normal, the urinary secretion of metanephrines did not fall to levels as low as those recorded after operation. This may be due to incomplete enzymatic blockade or to interference by urinary metabolites of $\alpha$-methyltyrosine with metanephrine assay.

\section{References}

' Ross EJ, Prichard BNC, Kaufman L, Robertson AIG, Harries BJ. Pre-operative and operative management of patients with phaeochromocytoma. Br Med J 1967;i:191-8.

${ }^{2}$ Dagget $\mathrm{P}$, Verner I, Carruthers $M$. Intraoperative management of phaeochromocytoma with sodium nitroprusside. $\mathrm{Br}$ Med J 1978;ii: 311-3.

${ }^{3}$ Van Vliet Pd, Burchell HB, Titus JL. Focal myocarditis associated with phaeochromocytoma. N Engl J Med 1966;274: 1102-8.

${ }^{4}$ Sjoerdsma A, Engelman K, Spector S, Udenfriend S. Inhibition of catecholamine synthesis in man with alpha-methyl-tyrosine, an inhibitor of tyrosine hydroxylase. Lancet 1965;ii:1092-4.

${ }^{5}$ Engelman K, Horwitz D, Jequier E, Sjoerdsma A. Biochemical and pharmacologic effects of alpha-methyl-tyrosine. J Clin Invest 1968;1:577-594. 